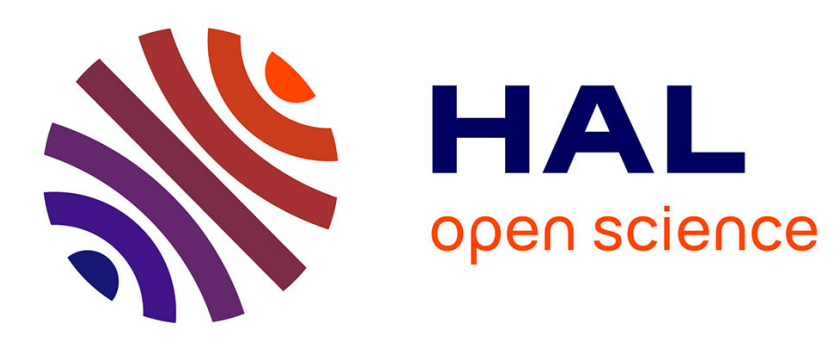

\title{
Numerical and Experimental Study of Early Stages of the Failure of AlSi-Cast Alloys
}

\author{
N. Lippmann, S. Schmauder, P. Gumbsch
}

\section{To cite this version:}

N. Lippmann, S. Schmauder, P. Gumbsch. Numerical and Experimental Study of Early Stages of the Failure of AlSi-Cast Alloys. Journal de Physique IV Proceedings, 1996, 06 (C6), pp.C6-123-C6-131. 10.1051/jp4:1996612 . jpa-00254440

\section{HAL Id: jpa-00254440 https://hal.science/jpa-00254440}

Submitted on 1 Jan 1996

HAL is a multi-disciplinary open access archive for the deposit and dissemination of scientific research documents, whether they are published or not. The documents may come from teaching and research institutions in France or abroad, or from public or private research centers.
L'archive ouverte pluridisciplinaire HAL, est destinée au dépôt et à la diffusion de documents scientifiques de niveau recherche, publiés ou non, émanant des établissements d'enseignement et de recherche français ou étrangers, des laboratoires publics ou privés. 


\title{
Numerical and Experimental Study of Early Stages of the Failure of AlSi-Cast Alloys
}

\author{
N. Lippmann*,**, S. Schmauder** and P. Gumbsch* \\ Max-Planck-Institut für Metallforschung, Institut für Werkstoffwissenschaft, Seestrasse 71, \\ 70174 Stuttgart, Germany \\ ** Staatliche Materialprïfungsanstalt (MPA), University of Stuttgart, Pfaffenwaldring 32, 70569 Stuttgart, \\ Germany
}

\begin{abstract}
The failure mechanisms in different AlSi-cast alloys with varying microstructures of the Si-eutectic are studied by in-situ tensile tests in a scanning electron microscope. Failure criteria for the matrix and the Si-particles as well as the macroscopic fracture behaviour are determined on the basis of these observations. The critical failure stress of Si-particles is calculated by Finite Elemente modelling of the fracture behaviour of a large grained model alloy.

Crack initiation and subsequent crack propagation in the real microstructure of the technical alloys is then simulated using the recently introduced method of multiphase elements and an automatic element elimination technique. Experiment and simulation are in very satisfactory agreement.
\end{abstract}

\section{Introduction}

The mechanical properties of sub-eutectic AlSi-cast alloys are critically determined by the microstructure of the Si-eutectic. Lamellar particles which are usually present in the eutectic can be modified by addition of antimony ( $\mathrm{Sb}$ ) to obtain a globular structure [1]. The fracture behaviour is hereby remarkably improved which is reflected in an increase of the critical strain to failure from $1 \%$ in the non-modified to $13 \%$ in the Sb-modified structure. These observations are well known from macroscopic tensile tests. The effect of the particle shape on crack initiation in the micro range, however, is not yet well understood.

With respect to the optimisation of the mechanical properties it is necessary to obtain an understanding of the failure mechanisms on a microscopic scale. The analysis of the structurally determined fracture behaviour is the objective of the experimental and numerical microstructural investigations presented in this paper. Modelling of real microstructures with the Finite Elemente Method (FEM) permits the simulation of special fracture initiating conditions including the presence of several phases as well as external notches.

\section{Experimental and numerical procedure}

The failure mechanisms are investigated for the AlSi-cast alloys of the type AlSi7Mg with lamellar and $\mathrm{Sb}$-modified globular structure of the Si-eutectic (figure 1).

In-situ tensile testing in a scanning electron microscope (SEM) is a simple method to accurately investigate the course of events during the failure of such materials. However, it seems worth noting that the observations are limited to the surface region while the failure event may well occur in the volume of the material. The concentration of stress in a confined region is necessary to study 


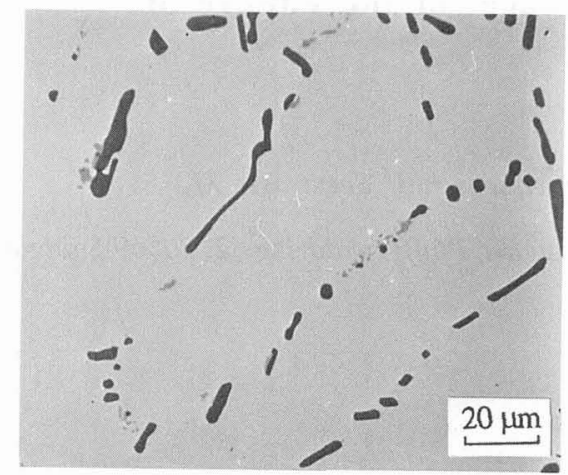

(a)

Figure 1: AlSi7Mg, (a) lamellar structure of the Si-eutectic, (b) Sb-modified, globular structure of the Si-eutectic.

all details of the crack initiation. Consequently, notched specimens with an elastic stress concentration factor of $\alpha_{K}=6$ and a slender ligament are used. The specimens are loaded in tension with a cross-head speed of $0.1 \mu \mathrm{m} / \mathrm{s}$ (figure 2).

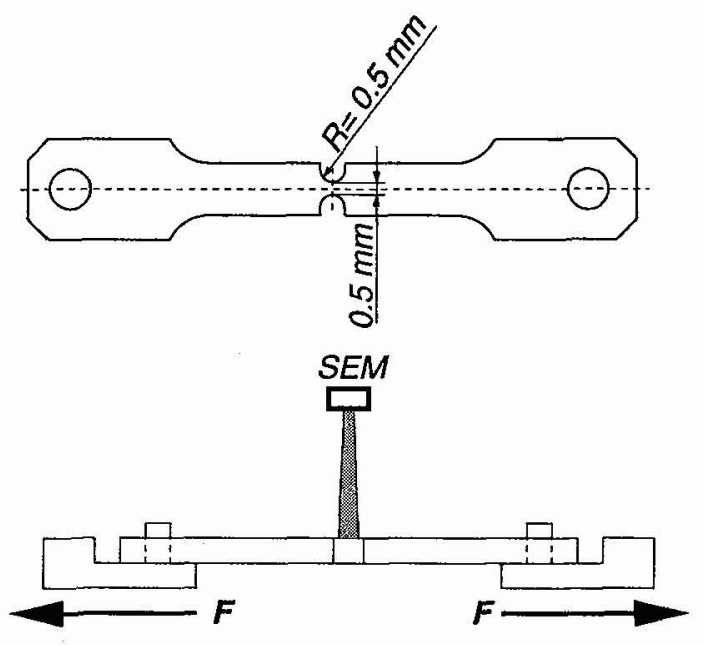

Figure 2: SEM in-situ tensile specimen and tensile test (schematic).

Crack initiation and subsequent failure of the microstructure is directly simulated by FEmodelling using

- the method of multiphase elements (MME) [2] in which the Gaussian points of one element may be assigned to different phases. (The FE-mesh can then be independent of the structure.)

- an automatic element elimination technique (EET) [3]. The crack path is simulated by the elimination of elements which exceed a predefined failure criterion.

The MME and EET were developed for use with the FE-program LARSTRAN [4] under plane strain boundary conditions. 
Material properties of the compound as well as of the individual microstructural constituents are needed as input parameters for the simulation. The stress-strain diagram for the AlSi-cast alloy was experimentally determined. A linear-elastic behaviour with a Young's modulus of $116 \mathrm{GPa}$ [5] is assumed for the Si-particles in the FE-models. The constitutive relation of the matrix is introduced in the calculations with the following functional dependence:

$$
\sigma=\sigma_{0}\left(\frac{E \epsilon}{\sigma_{0}}\right)^{n}
$$

where $\sigma_{0}$ is the yield stress (200 MPa), $\mathrm{E}$ is the Young's Modulus (70 GPa) and $\mathrm{n}$ is the strain hardening exponent $(0.25)$.

\section{Results}

\subsection{Experimental study of the failure process}

As expected, the alloy with the lamellar Si-eutectic shows macroscopically almost linear-elastic fracture behaviour. In the $\mathrm{Sb}$-modified structure elastic-plastic behaviour is observed macroscopically. Local yielding of the matrix is observed in the notch ground region at approximately $0.14 \%$ total strain. Brittle fracture of Si-particles occurs at $0.18 \%$ total strain (figure 3 ) in both alloys.

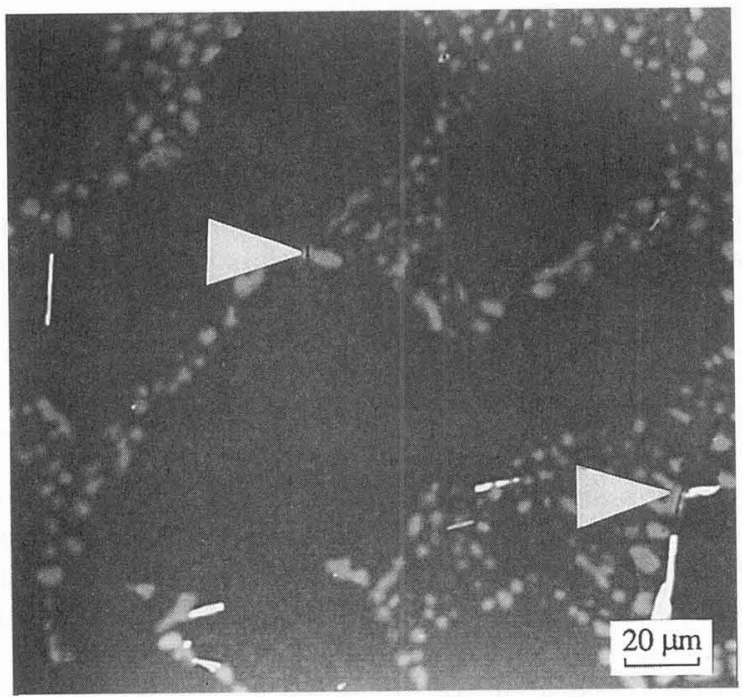

Figure 3: Crack initiation in the Si-eutectic by brittle fracture of particles (AlSi7Mg, Sb-modified).

Initial deviations from the linear-elastic behaviour in the stress-strain diagram are related to the brittle fracture of Si-particles. Especially in the notch ground region, a strong plastification of the matrix in conjunction with particle failure is observed. An example is depicted in figure 4.

Metallographic investigations of the fracture surfaces in the centre of the specimen are performed to study the failure mechanisms under plane strain conditions. Broken Si-particles at the fracture surfaces confirm the dominating role of Si-particles as fracture initiating defects. 


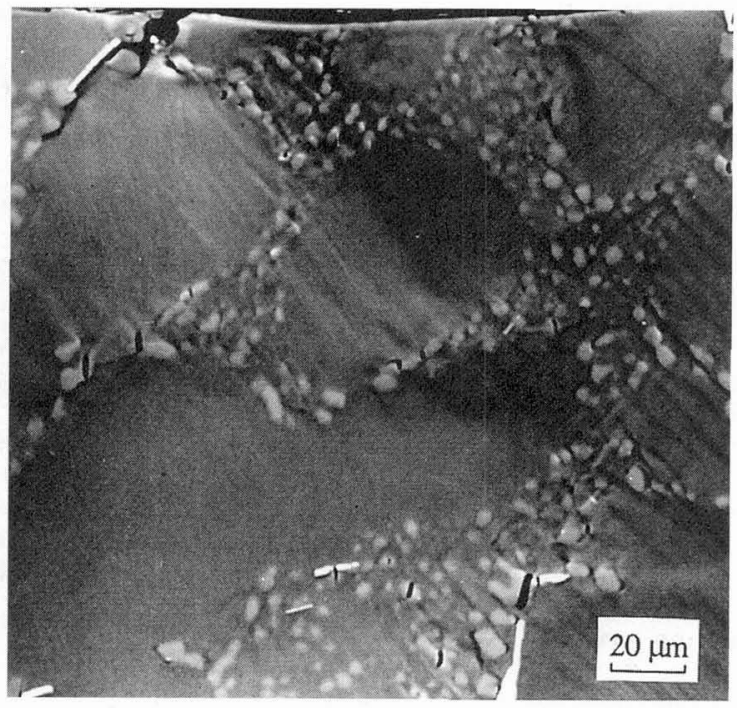

Figure 4: Particle cracking and local yielding in the notch ground region (AlSi7Mg, Sb-modified).

Particles with the longest axis parallel as well as perpendicular to the direction of normal stress break at about the same load although the geometry of the particles would favour the failure of particles aligned to the loading direction.

The Si-particles appear to be the "weak link" in the microstructure. The different macroscopic fracture behaviour of both alloys can be explained by the different shape of the particles. For small globular Si-particles, the cracks formed by particle fracture are much shorter than for the lamellar Si-eutectic. In the lamellar Si-eutectic, the fracture of particles perpendicular to the loading axis immediately introduces relatively long, critical cracks which result in macroscopically brittle failure. In both microstructures, crack initiation is observed sometimes in the notch ground and sometimes in the centre of the specimen. This can be understood, since the stress distribution is dominated by the local conditions and is only weakly determined by the (mild) global stress concentration from the notch.

\subsection{Determination of the fracture stress of Si-particles}

Further SEM in-situ tensile tests are performed for an AlSi17Cu alloy with large, primary precipitated Si-particles. The fracture of these particles can be observed more easily and thus be correlated to the globally applied fracture load. Since the tests are performed in-situ in a SEM, the geometry of fractured Si-particles and their location with regard to the notch ground is known. Assuming the average material properties of the AlSi-cast alloy and plane stress conditions, the stress components $\sigma_{x}$ and $\sigma_{y}$ in the region where the particle is located are calculated for the specimen at the global load which caused particle fracture.

Next, a model which takes into account the different mechanical properties of the two phases is generated in the FE-program LARSTRAN using the MME in order to calculate the failure stress of the Si-particles. This microscopic simulation cell includes three Si-particles (figure 5) and is loaded with the stresses determined in the previous macroscopic model. 

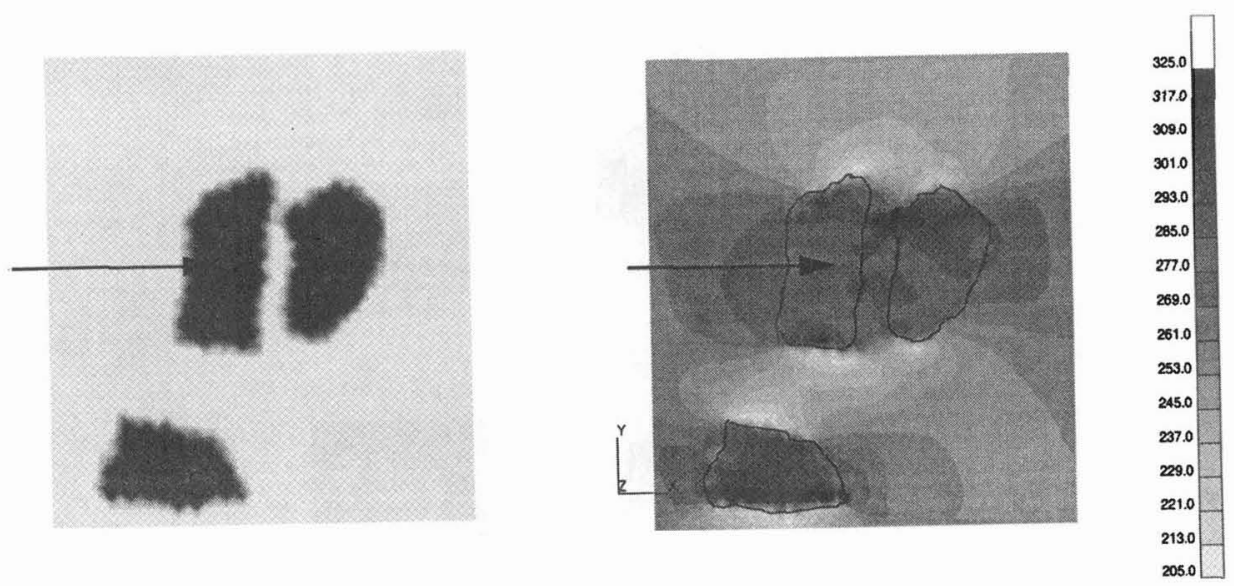

Figure 5: Microscopic FE-model for the calculation of the failure stress of Si-particles and calculated stress distribution at the particles (arrow $=$ cracking particle).

The stress in the particle is therefore calculated directly at the fracture initiating load. Assuming a normal stress criterion for brittle fracture a failure stress of about $310 \mathrm{MPa}$ is determined which is used as the failure criterion for the Si-particles in the FE-simulations of the crack initiation.

\subsection{Simulation of crack initiation}

Crack initiation is simulated on the basis of the SEM in-situ tensile tests of technical AlSi7Mg alloys with lamellar and globular structures of the Si-eutectic. Using the MME, cells representative of the two-phase microstructures are embedded into the central region of a $2 \mathrm{D}$-model of the in-situ tensile specimen with 15256 triangular elements (figure 6).

The different stages of crack initiation are simulated with a two-criteria model. Elements which are assigned to the Si-particles are eliminated on the basis of a normal stress criterion as determined in 3.2. A local damage parameter D based on Rice and Tracey's modified void growth model [6] is used as failure criterion for the subcritical crack growth in the matrix (eq. 2). In agreement with simulations of the crack path in an $\mathrm{Al} / \mathrm{SiC}$ metal matrix composite [7] the criterion for element elimination is set to $D \geq D_{c}=0.2$

$$
D=\int_{0}^{\epsilon_{p l}} e^{\frac{3}{2} \eta} d \tilde{\epsilon}_{p l}
$$

where $\eta=\sigma_{H} / \sigma_{V}$ is the stress triaxiality, $\sigma_{H}$ the hydrostatic stress, $\sigma_{V}$ the equivalent stress and $\epsilon_{p l}$ the plastic strain.

Figures 7 and 8 give an overview of the modelling of the early stages of failure for the lamellar and globular structure. As a result of the stress concentration the first cracks are formed in $\mathrm{Si}$-particles in the notch ground region at a total strain of about $0.2 \%$. In agreement with the experimental observations a large amount of Si-particles break before matrix failure occurs. At the tip of the cracks which are formed by particle cracking the damage parameter locally exceeds the critical value at higher total strains $(0.27 \%)$. In our model, this is the onset of crack propagation into the matrix by further element elimination. 

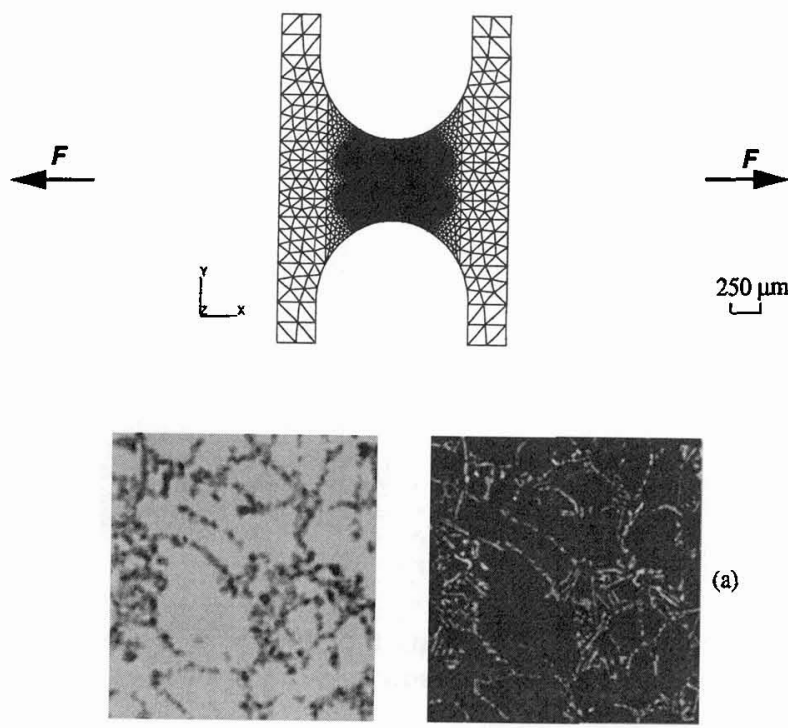

(a)
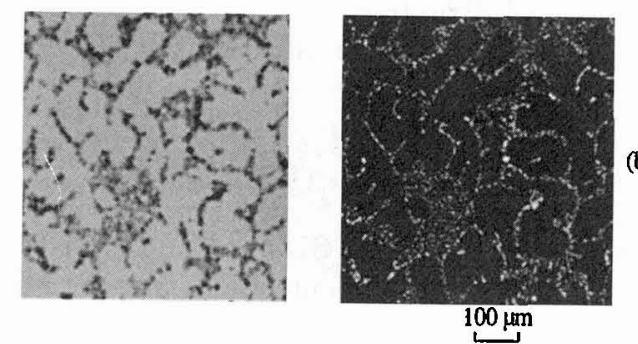

Figure 6: FE-model of the SEM in-situ tensile specimen and cells representative of the two-phase microstructure (assignment of phases to the Gaussian points in the elements) in comparison to the simulated structure, (a) AlSi7Mg (lamellar), (b) AlSi7Mg (globular).

Qualitatively, the calculation shows very good agreement with the experimental results. For the specimens simulated here, crack initiation was experimentally observed at a total strain of approximately $0.18 \%$ in both, the lamellar as well as the globular structure. The calculations give a total strain of $0.203 \%$ for fracture initiation in both structures. However, the location of crack initiation differs between the experiments, where the first crack is observed in the centre of the ligament, and the calculation, where crack initiation is located in the notch ground.

The crack path in AlSi7Mg with globular structure of the Si-eutectic is well reproduced in the simulations. The respective crack patterns are depicted in figure 9 for the experiment at about $0.45 \%$ total strain whereas the simulation predicts this crack path at a total strain of $0.337 \%$.

A large number of eliminated elements are assigned to Si-particles. Thus, failure of the simulated AISi-cast alloys is mainly determined by brittle fracture of the Si-particles in perfect agreement with the experimental observations.

The different fracture behaviour of the lamellar and globular microstructure is not fully reproduced in the calculations. With regard to the amount of eliminated elements at high total strains a similar macroscopic failure strain can be estimated in both microstructures (figures 7 and 8 ). However, the experimental failure strain is $60 \%$ higher in the case of the globular structure of the 

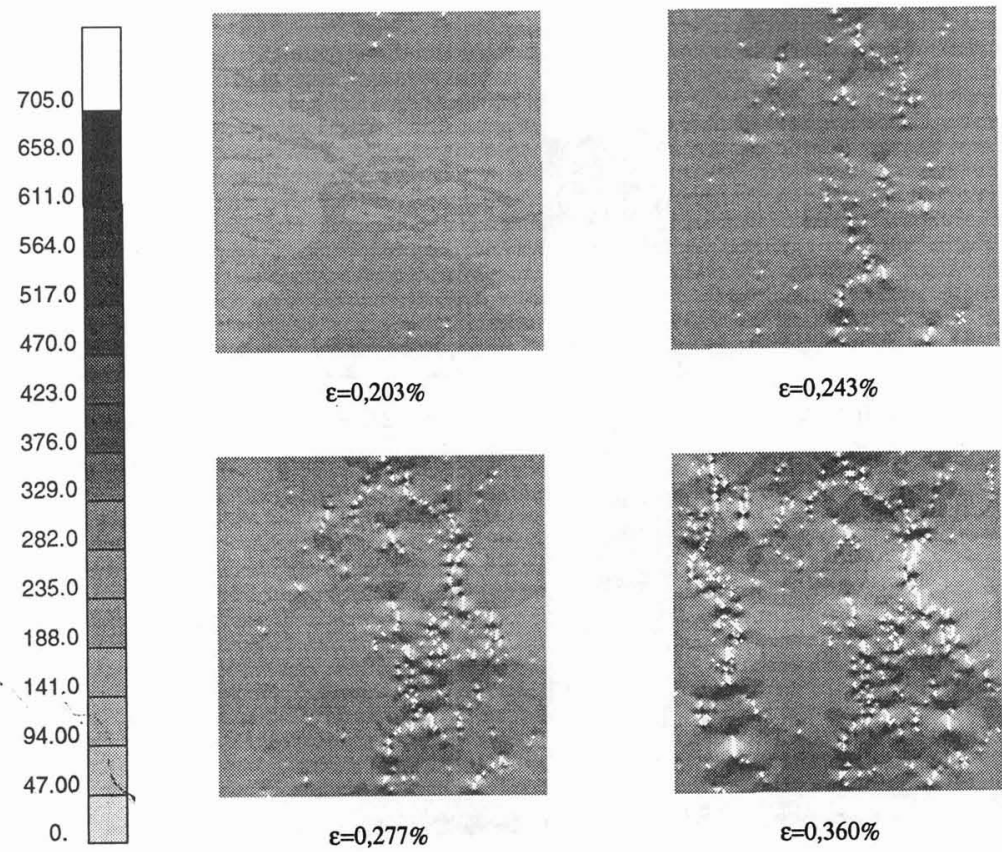

$\varepsilon=0,203 \%$

$\varepsilon=0,243 \%$
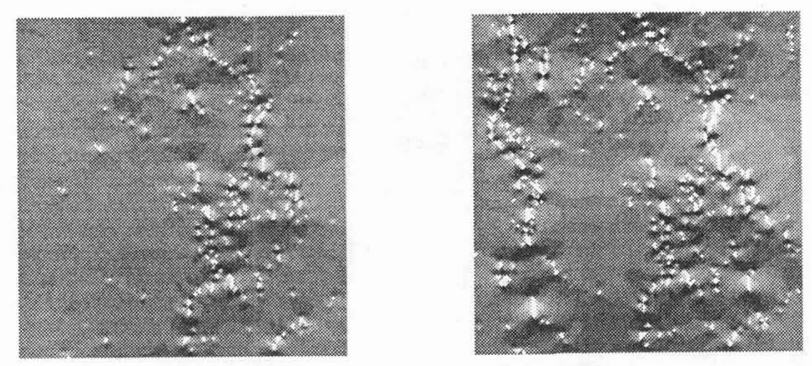

$\varepsilon=0,277 \%$

$\varepsilon=0,360 \%$

Figure 7: Simulation of crack initiation with eliminated elements (white) in AlSi7Mg (lamellar): stress distribution $\sigma_{x}$ at various total strains. Loading axis corresponds to figure 6 .

Si-eutectic. We attribute this to an insufficient resolution of the microstructure with our coarse mesh. As a result of the element edge length of approximately $6 \mu \mathrm{m}$ and a particle size of less than $3 \mu \mathrm{m}$ the particles are not reproduced accurately enough (figure 6). Furthermore, the anisotropy of strength of Si-particles is not included into the calculations.

Deviations between experimental results and calculation with regard to the location of cracks may be caused by the plane strain assumption as well as by the structure underneath the surface which emphasises the necessity of a fully 3D-analysis. Studies of 3D-microstructures are in preparation.

\section{Summary}

The failure mechanisms of AlSi-cast alloys of the type AlSi7Mg were studied experimentally and with corresponding FE-simulations. In-situ tensile tests performed in a SEM showed the different stages of failure: crack initiation by brittle fracture of the Si-particles, ductile crack growth by failure of the matrix and instable crack propagation.

The two alloys under consideration behave very differently. It was found that the failure of large lamellar particles may immediately form critical cracks which causes macroscopically a linear-elastic behaviour. The failure of globular particles introduces much shorter cracks which macroscopically results in an elastic-plastic behaviour. Assuming a normal stress criterion, the failure stress of the particles was estimated by FE-modelling and direct comparison with in-situ investigations on a model alloy with large Si-particles.

The fracture behaviour of a technical alloy was simulated using the method of multiphase elements and an automatic element elimination technique. Following the experimentally observed failure course, a two-criteria model was developed to simulate ductile and brittle failure at the same 

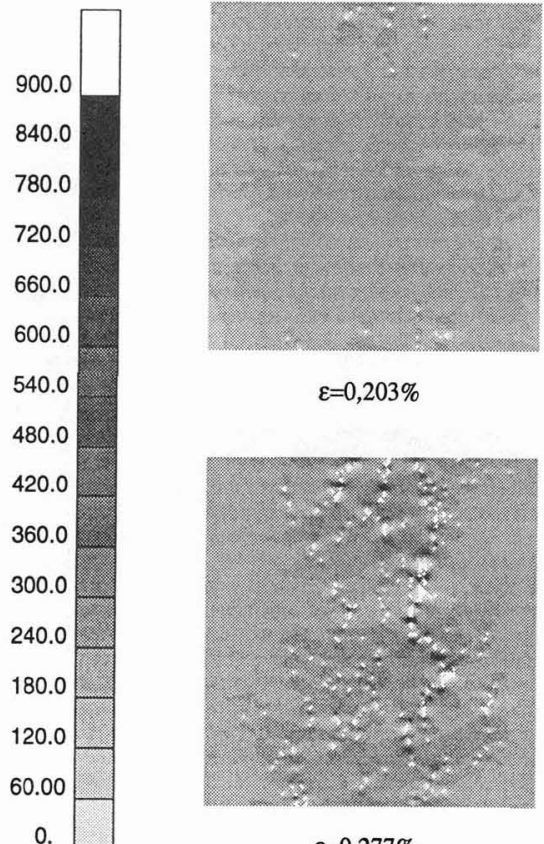

$\varepsilon=0,203 \%$

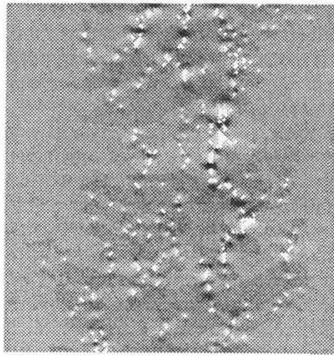

$\varepsilon=0,277 \%$

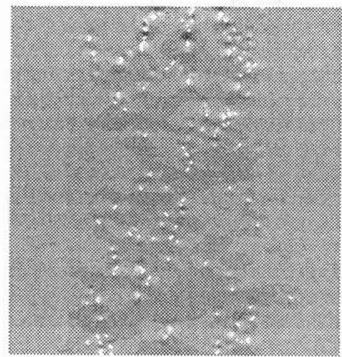

$\varepsilon=0,243 \%$

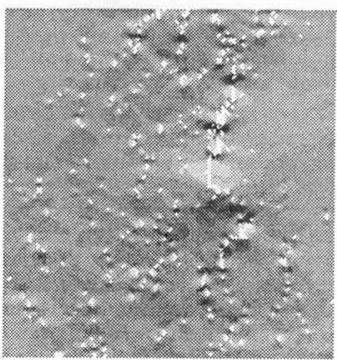

$\varepsilon=0,337 \%$

Figure 8: Simulation of crack initiation with eliminated elements (white) in AlSi7Mg (globular): stress distribution $\sigma_{x}$ at various total strains. Loading axis corresponds to figure 6 .

time. Failure of the Si-particles, occuring before matrix failure, was simulated by a normal stress criterion. Element elimination in the matrix was based on Rice \& Tracey's local damage parameter.

The results of the FE-simulation satisfactorily reproduce the experimental results with respect to the total strain which causes crack initiation. The calculated crack configuration in the globular structure agrees with the experimentally obtained crack patterns. However, the precise location of crack initiation and the different fracture behaviour of the AlSi-cast alloys with lamellar and globular structure of the $\mathrm{Si}$-eutectic are not yet reproduced accurately. An improvement of the results is expected by the use of plane stress conditions, an increase of mesh density and a fully $3 \mathrm{D}$-analysis.

\section{Acknowledgements}

This research work is part of the COST-512 program supported by BMBF (contract No. 03K 8004). The support of Robert Bosch GmbH, Fonderies Waeles and Lasso Ingenieurgesellschaft is acknowledged. 
(a)

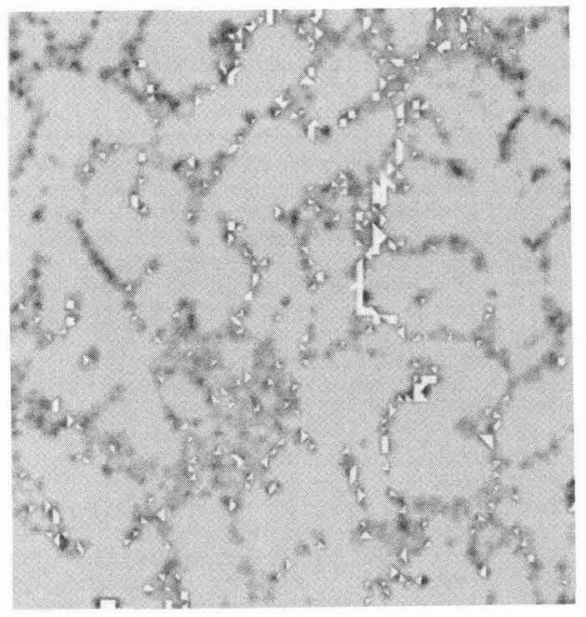

(b)

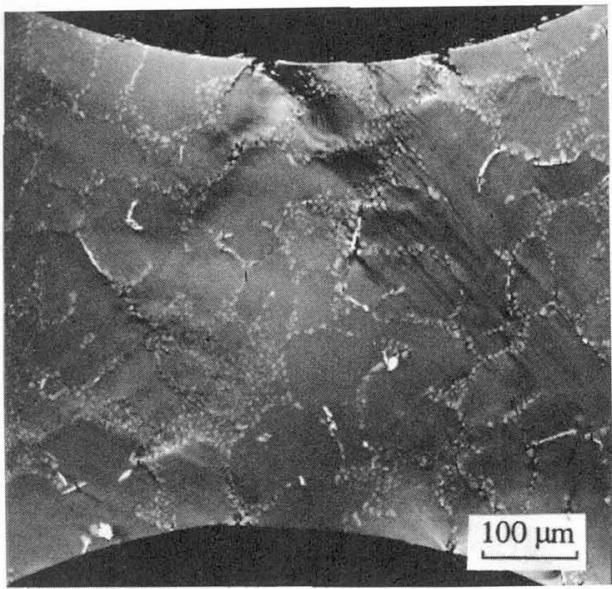

Figure 9: Crack path in AlSi (globular) - comparison of calculation (a) and experiment (b).

\section{References}

1. Reif, W.; Subramanyam, P. \& Schneider, W. Untersuchungen zur Feinungswirkung und zum Feinungsmechanismus von Antimon am Beispiel der Legierung G-AlSi7Mg, Gießereiforschung, 1993, 1, 9-18 and 65-72.

2. Steinkopff, Th. \& Sautter, M. Simulating the elasto-plastic behaviour of multiphase materials by advanced finite element techniques, Comp. Mat. Sci., 1995, 4, 10-14 and 15-22.

3. Wulf, J.; Steinkopff, Th. \& Fischmeister, H.F. FE-Simulation of Crack Paths in the Real Microstructure of an $\mathrm{Al}(6061) / \mathrm{SiC}$ Composite, Acta Met., 1995, 44, 1765-1779

4. LARSTRAN, LASSO Ingenieurgesellschaft, Leinfelden-Echterdingen, Germany.

5. Erinski, D.P. Untersuchungen über den Einfluß des Werkstoffgefüges auf das Zerspanverhalten von AlSi-Gußlegierungen, Dissertation RWTH Aachen, 1990.

6. Rice, J.R. \& Tracey, D.M. On the ductile enlargement of voids in triaxial stress fields, J. Mech. Phys. Solids, 1969, 17, 201-217.

7. Wulf, J. Neue Finite-Elemente-Methoden zur Simulation des Duktilbruchs in Al/SiC, Dissertation Universität Stuttgart, 1995. 